\title{
Student Epistemologies in Project-based Learning Courses
}

\author{
Gintaras Duda and Kristina Ward
}

\author{
Creighton University, 2500 California Plaza, Omaha, NE 68178
}

\begin{abstract}
Previous research has shown that problem/project-based learning (PBL) environments can effect positive changes in student attitudes and beliefs about learning. Although there has been interest in problem/project-based learning in the PER community as an active engagement strategy, most work done to date has focused on introductory courses with little attention paid to the transformation of student attitudes and epistemologies. Guided by this past work on PBL, this paper describes preliminary research in an upper-division quantum mechanics, a junior/senior level course at Creighton University, which was taught using PBL pedagogy with no in-class lectures. Growth and changes in student epistemologies as a result of the non-traditional pedagogy are presented. In particular, students emerged from a project-based course more confident in their abilities to dig into the textbook and seek out and find literature. Students reported that PBL pedagogy better prepared them to be in charge of their own learning. Finally, students felt more confident to confront realistic, research-like problems and to succeed in future graduate work.
\end{abstract}

Keywords: Project and/or Problem-based Learning, Student Attitudes, Pedagogy in Upper Division Courses PACS: 01.40.Fk, 01.40.gb

\section{INTRODUCTION}

An earlier paper by one of the authors (G.D.) examined student expectations for learning in project-based environments in upper division physics courses [1]. Here we take the next step and focus on the effects of projectbased learning (PBL) pedagogy on students' attitudes and epistemologies. This is an important question since educational and cognitive science research have shown that student attitudes and epistemologies can play a vital role in learning [2]. In general, student epistemologies mean a student's "set of views about the nature of knowledge, knowing, and learning in physics" [3]. For our purposes, by epistemologies here we restrict our meaning to students' perceptions and conceptions of their own learning and knowing, in addition to their overall sense of professionalism in the continuum from novice to expert physicists. We make the explicit theoretical assumption that student epistemologies are stable and coherent, and that students "grow" in their epistemological sophistication and depth as they progress through different stages (such as novice to journeyman to expert). Although epistemologies can be context dependent, we are interested only in students' beliefs about their own learning in the upper division physics PBL classroom, and restrict our attention there.

Much of the work done on student epistemologies in physics is based on the work of Hammer [4], who established a set of epistemological dimensions which grew out of student observations and interviews. These dimensions are: 1) formulas vs. concepts, 2) pieces vs. coherence, 3) transmissionist vs. constructivist (authority vs. independence), and 4) innate vs. effort. We have ob- served that many upper division students have already made large epistemological gains compared to introductory physics students in terms of Hammer's first two dimensions; they are much less likely to hold to a collection of formulas concept of physics and to a lesser extent are generally looking for coherence in physics. However, as these students move into more abstract upper division courses, they are less likely to see the real-world applicability of the physics they are studying.

But why study student epistemologies in the context of PBL courses? Despite the success of PBL in other disciplines, in physics PBL has been restricted to the introductory physics sequence, i.e. mechanics and topics in electricity and magnetism. Little work has been done in studying the effectiveness, and even the appropriateness of PBL at the upper division or graduate level. In fact, a search of the physics education literature reveals a limited number of such experiments, in which modules were implemented in an introductory thermodynamics and mathematical physics course using PBL $[5,1]$. And yet, project-based learning offers tremendous advantages to students as an example of a systematic, active engagement pedagogy which differs from more traditional, lecture-based strategies. This is of crucial importance since many, if not most, upper division courses are still taught in a lecture format even if supplemented by activeengagement activities. The educational and cognitive science research have clearly shown that active, studentcentered approaches are necessary for deep and effective learning [6]. Project-based pedagogy can be thought of as radical in the sense that it eschews the traditional lecture format entirely, and instead of short snippets of active-engagement episodes in a class period, $100 \%$ of 
class time is student centered and active. In one sense, studying PBL at the upper division level can help further answer the question of "How active is active enough?"

More concretely, research on PBL makes the claim that PBL environments are extremely effective in developing self-directed and self-regulating learning in students, i.e. moving their epistemological sense of learning from the transmissionist to the constructivist (or from authority to independence) and from the innate to the effort ends of the spectrum [7]. In upper division physics courses we particularly care about developing students' identities as self-directed learners (i.e. researchers); this makes the transfer of physics to other disciplines much more effective in addition to easing the transition from student to researcher which occurs when first working on research projects or in graduate study. Therefore, in this work our fundamental research question is does PBL pedagogy in upper division physics positively impact students' epistemological sense of learning?

\section{PROJECT-BASED QUANTUM MECHANICS}

The draw of project-based learning in physics is that classroom instruction more naturally resembles the organic process of research and how physics is done in the real-world: students confront purposeful, open-ended, and ill-defined problems whose answers shed light on an interesting situation/question. Barbara Dutch and collaborators at the University of Delaware have done groundbreaking work on adapting this pedagogy to physics instruction [8]. For example, one particularly useful resource developed at the University of Delaware is the PBL Clearinghouse [9]. For a brief review of the basics of PBL, see in particular [10].

Quantum mechanics at Creighton University is a typical, one-semester long course for junior and senior physics majors. The course content covers solutions to the Schrodinger Equation, ranging from the onedimensional infinite square well, finite square well, and harmonic oscillator, through the hydrogen atom with some coverage of spin. Typical enrollments have been on the order of 6-12 students. Past incarnations (prefall 2011) of the course have been lecture-based with an optional recitation section devoted to problem solving along with active-engagement strategies included in lecture such as the use of clicker questions or tutorials. However, beginning in 2011 the course was transformed to a project-based learning course with no class time dedicated to standard lectures. Instead students learn primarily through projects coupled with in-class lecture tutorials which cover basic systems and calculations in quantum mechanics. The lecture tutorials build on work by
Timberlake [11] (and are the subject of ongoing collaboration), and include pre-class activities, an in-class tutorial, and a metacognitive self-assessment to be completed after each tutorial. The metacognitive self-assessments were added in recognition of cognitive science research that has shown that metacognitive knowledge monitoring and self-regulation are essential in learning new knowledge and represent practices employed by the most successful learners [12]-[13].

Previous research on the feasibility of using projectbased pedagogy in upper division physics courses suggested that students could succeed in such an environment, but that their success depended to a large degree on sufficient scaffolding and organization[1]. In this specific case, weekly scaffolding is provided to students through packets that include suggested reading in the textbook, notes on said reading that highlight essential points, weekly homework, worked example problems, and historical papers and other excerpts from the literature. The projects (four to five per semester) are still the focus of the course and provide motivation for learning the bits and pieces of quantum mechanics that go into solving a larger problem. For example, one of the first projects in the course (for the section on solutions to the one-dimensional Schrodinger Equation) is the radioactive decay of the Uranium atom and Gamow's insight that quantum mechanical tunneling explains the problematically low energy of the emitted alpha particle. With the solution to this problem in mind, students learn how to solve the 1D Schrodinger Equation, work through traditional examples that teach them about energy quantization like the infinite and finite square wells, and then try their hand at basic scattering (from potential steps). All of these skill-building steps are motivated by the project and put their learning into context. All of the work during class time is done in small groups of typically 3 students. The projects culminate in some sort of deliverable, either formal, journal-type articles written using $\mathrm{LTT}_{\mathrm{E}} \mathrm{X}$, or oral or poster presentations. Students complete assessments of their teams using the online CATME website and reflect on their learning, experience, and growth electronically using our campus LMS. Reflective exercises were interspersed throughout the semester and consisted of a beginning of the semester goal-setting exercise, postproject reflections, and a summative end-of-semester reflection in which students examined their initials goals for the course and chronicled their growth and accomplishments. For more details about student reflections in this course, see the companion article in the conference proceedings titled "The Role of Student Reflection in Project-based Learning Physics Courses". 


\section{GETTING AT STUDENT ATTITUDES AND EPISTEMOLOGIES}

To study student attitudes and epistemologies in the project-based quantum mechanics course, data were gathered through a combination of surveys, guided written reflections, focus groups, and individual student interviews. Since quantum mechanics at Creighton is taught only in the fall semester and enrollments are small (typically 6-8 students), it is difficult to study student attitudes using quantitative methods or the usual surveys designed for large courses like the CLASS or MPEX2. For example, data from the CLASS survey shows that students begin the course with near expert-like beliefs (not surprising given that these are junior and senior physics majors), and that shifts in most categories are not statistically significant.

In the spring of 2014 we surveyed all of the graduates of the PBL quantum mechanics course at Creighton since 2011 (a total of 22 students). Of these, we were able to collect responses from 15; several were out of the country, and all but six students had graduated and left the university. Given the circumstances, we feel that a $68 \%$ response rate on an electronic survey is extremely high. The survey focused on three areas: 1) mastery of content and skills, 2) usefulness of reflections in the course, and 3) changes in student attitudes and epistemologies. As can be seen in Tables (1) and (2), $86.6 \%$ of students reported that they felt they grew as physicists, and $80 \%$ said they were more prepared to learn on their own due to the PBL pedagogy employed in the course. On the transmissionist vs. constructivist dimension, more than $80 \%$ of the students surveyed reported that they were more able to take charge of their own learning and to be active learner.

Given the low student numbers, we turned also to a more qualitative analysis. We conducted several focus group sessions in which nine students were able to participate, followed by several one-on-one interviews. We also collected data on student attitudes and sense of self and professionalism from reflective exercises during the semester. The reflective exercises were coded using a reflection hierarchy from the educational literature devised by Valli [14]. Here we concerned ourselves only with what Valli labels "personal" and "deliberative" reflections, since these are the types of reflections that will give us the most insight into changes or growth in student attitudes and epistemologies. Similar to the work of Etkina and May [15], we coded the reflections, focus groups, and interviews for evidence of shifts in personal epistemologies regarding learning and the generation of knowledge. In reflections students were quite vocal about their perceived growth and the personal impact the course had on them:
TABLE 1. Student Responses to selected Likert-Scale survey questions $(\mathrm{N}=15)$. The question reads "Project-based pedagogy used in this class contributed to my growth as a student/physicist in the following areas:"

\begin{tabular}{lccc}
\hline $\begin{array}{l}\text { Survey } \\
\text { Question }\end{array}$ & $\begin{array}{c}\text { Strongly } \\
\text { Agree }\end{array}$ & Agree & Neutral \\
\hline Content Mastery & $33.3 \%$ & $40.0 \%$ & $26.7 \%$ \\
\hline Scientific Writing & $53.4 \%$ & $33.3 \%$ & $13.3 \%$ \\
\hline Sense of professionalism & $46.7 \%$ & $26.7 \%$ & $26.6 \%$ \\
\hline $\begin{array}{l}\text { Taking charge of } \\
\text { my own learning }\end{array}$ & $46.7 \%$ & $33.3 \%$ & $20.0 \%$ \\
\hline $\begin{array}{l}\text { Being an Active } \\
\text { Learner }\end{array}$ & $46.7 \%$ & $40.0 \%$ & $13.3 \%$ \\
\hline $\begin{array}{l}\text { See real-world } \\
\text { connections }\end{array}$ & $46.7 \%$ & $33.3 \%$ & $20.0 \%$ \\
\hline $\begin{array}{l}\text { More interested } \\
\text { in QM }\end{array}$ & $53.3 \%$ & $13.3 \%$ & $33.3 \%$ \\
\hline $\begin{array}{l}\text { More confidence } \\
\text { to do physics }\end{array}$ & $46.7 \%$ & $33.3 \%$ & $13.3 \%$ \\
\hline
\end{tabular}

TABLE 2. Student Responses to selected Likert-Scale survey questions $(\mathrm{N}=15)$ that dealt with reflection or changes in epistemologies.

\begin{tabular}{lccc}
\hline $\begin{array}{l}\text { Survey } \\
\text { Question }\end{array}$ & $\begin{array}{c}\text { Strongly } \\
\text { Agree }\end{array}$ & Agree & Neutral \\
\hline $\begin{array}{l}\text { I felt I grew } \\
\text { as a physicist }\end{array}$ & $46.6 \%$ & $40 \%$ & - \\
\hline $\begin{array}{l}\text { More prepared to } \\
\text { learn on my own }\end{array}$ & $33.3 \%$ & $46.7 \%$ & $20.0 \%$ \\
\hline $\begin{array}{l}\text { More able to } \\
\text { tackle complicated, } \\
\text { real-life problems }\end{array}$ & $40.0 \%$ & $40.0 \%$ & $20.0 \%$ \\
\hline $\begin{array}{l}\text { Should do more } \\
\text { reflection in } \\
\text { physics courses }\end{array}$ & $26.7 \%$ & $33.3 \%$ & $13.3 \%$ \\
\hline
\end{tabular}

"I did learn a lot! Some about quantum but much much more about myself."

"I've gone beyond the requirements in some classes just because I thought this application would be cool to use or that I simply wanted to learn more about the subject. I've never been in such challenging course, never been feeling so confident about my school work, and never been enjoying working so much."

"What I learned about myself was that I work best when challenged."

"I'd say I developed an ability to connect the dots where information or understanding is missing."

Student interviews and focus groups also shed light on 
shifts in students' epistemologies. Students commented particularly on themes revolving around their own active learning and hard work, and how the course reinforced a more constructivist epistemology. For example, one student commented that the ill-defined nature of the projects taught him that

"Science is not just here's the procedure from the book and fill in the steps between, right? You can go off in a different direction and stumble back."

The same student continues,

"Out of the class that's what I got mainly out of it. At first everything seems a bit free for students, and it forces you to see what's out there to solve a problem, right? And, uh, I think it actually helped me in my own research not just in the research itself but how to acquire data and how to look for data and that was actually really helpful. The idea of going in blind into a project you don't know what you're doing and you don't master the concepts first - was really important as part of the experience. Because whenever you're actually doing innovative research you're more or less blind - the material you're doing is not mastered and not understood."

To which another student responded,

"It helps you not to freak out when you don't know the answer right away."

One student in the 2013 quantum course was an interesting case of a very gifted upper division physics student with a deeply entrenched transmissionist attitude about learning. This student had a great deal of difficulty in the course, despite his intellectual gifts, not so much with the material but rather with the purposely vague projects and the self-directed learning elements. He says,

"I know that was one of the difficulties I had with the course - um - was the sort of the lack of lecture-based instruction, because I feel like I've invested a lot into getting good at learning in a lecture-based environment. Um, so I felt like there was a tension at least for me between this class as learning in terms of the traditional educational path - learning the topic - versus as a tool for professional development and to get better at doing the science rather than just learning the material. For me this was the primary struggle I had for the course - trying to rectify the idea of this as making me a better scientist and physicist versus feeling like I was floundering a bit for the course material itself."

As Elby points out "students' views about learning are entangled with self-efficacy, their views about their own abilities" [3]. This student was deeply suspicious of PBL at first, and spent much of the semester wishing out loud for lectures. This student, however, was not unfamiliar with project-based pedagogy, having successfully completed a year-long integrated calculus-physics sequence (Modeling the Physical World) in his first year. The difference was that the first-year modeling course had a significant lecture component, and quantum mechanics was lecture-free and completely project-based. But by the end of the course, as hinted to above, he comes to recognize the advantages of the alternate pedagogy and opens up to the possibility of epistemological growth as an positive outcome of the course. During a focus group, when asked about his comment, the student replied that knowing that such growth was a chief objective for the course made him feel better about his experience. PBL pedagogy forced him to confront this particular attitude towards learning. Clearly here too we have an entanglement of epistemology and expectations that future research will need to untangle.

\section{CONCLUSIONS/FUTURE PLANS}

Data from three semesters of a PBL version of quantum mechanics seems to support the hypothesis that selfdirected learning required by PBL helps students shift more towards the constructivist and effort ends of the spectrum in terms of their epistemologies. Students additionally seem to be more comfortable with the fundamental uncertainties associated with actually doing science and scientific research. We plan to expand this preliminary study in the future through collaboration with mathematics and energy science faculty at Creighton who are also exploring the use of PBL pedagogies in their classrooms, as well as working with collaborators to study other quantum mechanics undergraduate courses elsewhere.

\section{REFERENCES}

1. G. Duda and J. Ross, AIP Conf. Proc. 1413, 183-186 (2011).

2. T. Koballa and F. Crawley, Sci. Ed. 78, 35-55 (1994).

3. A. Elby in Getting Started in PER, ed. by C. Henderson and K. Harper (AAPT, College Park, MD, 2011), Reviews in PER Vol. 2.

4. D. Hammer, Cog. and Instruc. 12 (2), 151-183 (1994).

5. P. VanKampen et al., Am. J. Phys. 72, 829-834 (2004).

6. S. Freeman et al., Proc. Natl. Acad. Sci. USA 111 (23) 8410-8415 (2014).

7. M. English and A. Kitsantas, Int. J. of Problem-Based Learning 7 (2), 128-150 (2013).

8. B. Dutch, J. Coll. Sci. Teach. 26, 529-541 (1996).

9. The PBL Clearinghouse: https://primus.nss.udel.edu/Pbl/

10. J. Savery, Int. J. of PBL 1 (1), 9-20 (2006).

11. T. Timberlake, invited talk given at the 2011 Summer Meeting of the AAPT, Omaha, NE (2011).

12. P. Pintrich, Theory into Prac. 41 (4), 219-226 (2002).

13. B. Zimmerman, Theory into Prac. 41 (2), 64-72 (2002).

14. L. Valli, Peabody J. of Ed. 70 (1), 67-88 (1997).

15. D. May and E. Etkina, Am. J. Phys. 70 (12), 1249 (2002). 